\title{
Temperature Augmented Visual Method for Initial Screening of Hydrate Inhibitors
}

\author{
Tinku Saikia and Vikas Mahto* \\ Department of Petroleum Engineering, Indian Institute of Technology (Indian School of Mines), Dhanbad 826004 - India \\ e-mail: vikas.ismpe@hotmail.com \\ *Corresponding author
}

\begin{abstract}
The formation of gas hydrates in oil \& gas pipelines and drilling fluid flow lines is a major issue in the petroleum industry. Gas hydrate inhibitors are normally used to inhibit the formation of gas hydrates in the pipelines/flowlines. Initial screening of hydrate inhibitors and AntiAgglomerants (AA) requires a safe and economical experimental setup/method. Conventional visual method was used for initial screening of hydrate inhibitors in many researches. Some researchers also suggested modified visual methods, but all of them lacks accurate measurement of induction time and found to be inappropriate for experimental solutions like drilling mud, etc. In this work, a temperature augmented visual method was presented which can be used in academic research laboratories for study and initial screening of hydrate inhibitors. This method is capable of parallel screening of inhibitors and determines hydrate induction time precisely. Experiments were conducted to determine the hydrate induction time of different inhibitors using augmented method and compared with conventional visual method. The developed method found to be more precise in determining the induction time of hydrates in all types of experimental solutions.
\end{abstract}

\section{INTRODUCTION}

Gas hydrate is a crystalline solid in which larger host molecules such as water captures smaller non polar guest molecules (e.g. methane, ethane) in the polyhedral cavities of its framework [1]. Gas hydrates are found in three different types of crystallographic structures, first two are sI and sII, which are cubic structure and the third one is hexagonal sH structure. Usually, cubic hydrate structures are important in the oil \& gas industry. The structure of the hydrate depends upon the inclusion of smaller (guest) molecules [1].

In the upstream oil industry, the formation of hydrates in the pipelines and drilling fluid flow lines may cause blockage or even unrecoverable accidents. The hydrate formation in pipelines not only raises safety concerns, but, also leads to economical losses. During drilling of gas hydrate bearing formations, drilling fluid was subjected to the gas hydrate stability zone where the formation of gas hydrates was inevitable. It not only causes changes in the drilling fluid rheology, but, also leads to blockage of flowline, etc. [2,3]. This formation of gas hydrates may also lead to drilling accidents due to a blowout in the oil \& gas wells. Different reported drilling accidents like blowouts in Santa Barbara, California and Green Canyon, Gulf of Mexico are caused due to gas hydrates [4]. To prevent the hydrate formation in drilling fluid, different techniques were proposed with time such as cooling the drilling fluid, decreasing circulation rate and use of gas hydrate inhibitors, etc. But, out of all these techniques except for gas hydrate inhibitors, all the others are proved to be ineffective and uneconomical to use [5].

Gas hydrate inhibitors are broadly classified as Low Dosage Hydrate Inhibitors (LDHI) and thermodynamic inhibitors [6]. LDHI are again subdivided as kinetic inhibitors and AntiAgglomerants (AA). Thermodynamic 
inhibitors inhibit hydrate formation by shifting the dissociation curve outside the hydrate stability zone, i.e. higher pressure and lower temperature. Whereas, kinetic inhibitors only delay the nucleation of hydrates and restricts the growth of hydrate crystals [7]. AA do not restrict the hydrate formation, but prevents the hydrate crystals from agglomerating and accumulating into huge masses [6]. For effective hydrate inhibition large amount of thermodynamic inhibitor is required, sometimes upto $50 \mathrm{wt}$ $\%$ [8]. Thermodynamic inhibitors also adversely affect the environment and with the exploration of oil \& gas in deeper horizons, they are becoming uneconomical for field application. Kinetic inhibitors are LDHI and effective even at lower concentrations of less than $1.0 \mathrm{wt} \%$ [9]. But, both the types of inhibitors are not much more effective under a greater degree of supercooling and higher pressure. Chemical surfactants were usually used as AA, but they are toxic and not biodegradable [10]. Hence, there is an urgent need of finding new inhibitors and AA, which are environment friendly and much more effective at greater depths $[11,12]$. To identify new hydrate inhibitors/AA and rank their efficiency, a number of experimental techniques/ setups are available such as, stirred batch reactors, autoclaves, rocking cells and high pressure automated lag time apparatus, etc [13-17]. But, all these setup possess major drawbacks such as, highly flammable gases used, works at high pressure, long data acquisition time, large sample requirement and these setups are very costly for any academic research institute. Different researchers proposed different new techniques for easy detection of formation and inhibition of hydrates in the experimental solution. Park and Kim, 2013 propose the use of ultrasonic waves for the detection of gas hydrates [18]. Zhou et al., 2007 use electrical resistance measurement technique and Liu et al., 2010 use MRI technique for the detection of methane/ TetraHydroFuran hydrate formation respectively [19, 20]. Karamoddin and Varaminian, 2014 use measurement of electrical conductivity technique for hydrate detection [21]. Zeng et al., 2006 use NMR microscopy techniques for the detection of gas hydrate crystals [22]. All these methods use sophisticated instruments for gas hydrate detection. The easy and economical way to determine the gas hydrate formation was by visual method. Few researchers suggested different modified visual detection method for initial screening of hydrates using TetraHydroFuran (THF) hydrates [16, 23]. Pakulski, 1997 states that screening of hydrate inhibitors can be effectively done with THF hydrates by decreasing the variability in results [24]. Maeda et al., 2016 presents a modified version of visual methods in which parallel fast screening of different hydrate inhibitors can be done with ease, but the detection of hydrate induction and growth was identified only visually [16]. Abojaladi and Kelland, 2016 presents an experimental study that shows the visual method can be used for initial screening of anti-agglomerant using cyclopentane hydrates [25]. The main drawback of the visual detection method is the measurement accuracy of hydrate induction time. In these methods, the induction of hydrate crystals was identified visually after the hydrate crystal becomes large enough to be seen by naked eyes, which causes a lag in the detection of actual induction time. This lag may cause error in the determination of induction time of hydrates. Moreover, if the experimental solution is a colored solution (like drilling fluid, etc.) then it was very difficult to verify the formation of hydrate crystals visually and accurate determination of the induction time in the solution is not possible.

THF hydrate formation process shows exothermic character and homogeneous heat release [26]. This characteristic of THF hydrate was effectively utilized in the developed method. This research article presents a method in which visual detection of hydrates was augmented with real-time temperature measurement to obtain more accuracy in the determination of hydrate induction time and initial screening of hydrate inhibitors in all types of experimental solution with pace. Moreover, in this method all the stages of hydrate formation can be easily determined in the experimental solution by measuring the temperature change.

\section{MATERIALS AND EXPERIMENTAL PROCEDURE}

\subsection{Materials}

THF was purchased from Central Drug House Pvt. Ltd, New Delhi. The kinetic inhibitors studied in this research work were PolyVinylPyrrolidone (PVP K-15) purchased from Tokyo Chemical Industry Co. Ltd, Poly(N-IsoPropylacry1AMide) (PNIPAM) was purchased from Sigma Aldrich, St. Louis, MO, USA. PolyAcrylaMide (PAM) was purchased from Central Drug House Pvt. Ltd, New Delhi and Luvicap $55 \mathrm{~W}$ was purchased from BASF Chemicals. The experimental solution used for hydrate inhibition test was a mixture of TetraHydroFuran and distilled water.

\subsection{Experimental Procedure}

\subsubsection{Temperature Augmented Visual Method for Hydrate Induction Time Studies}

The self fabricated setup used for clathrate hydrate induction time study is shown in Figure 1. In the experimental setup, the experimental solution was kept in a $500 \mathrm{ml}$ jacketed glass beaker. The temperature of the experimental solution was maintained by circulating coolant (Ethylene glycol $20 \mathrm{Vol} \%$ in distilled water) from the cold bath to the jacket of the glass beaker. Continuous stirring of the experimental solution was 


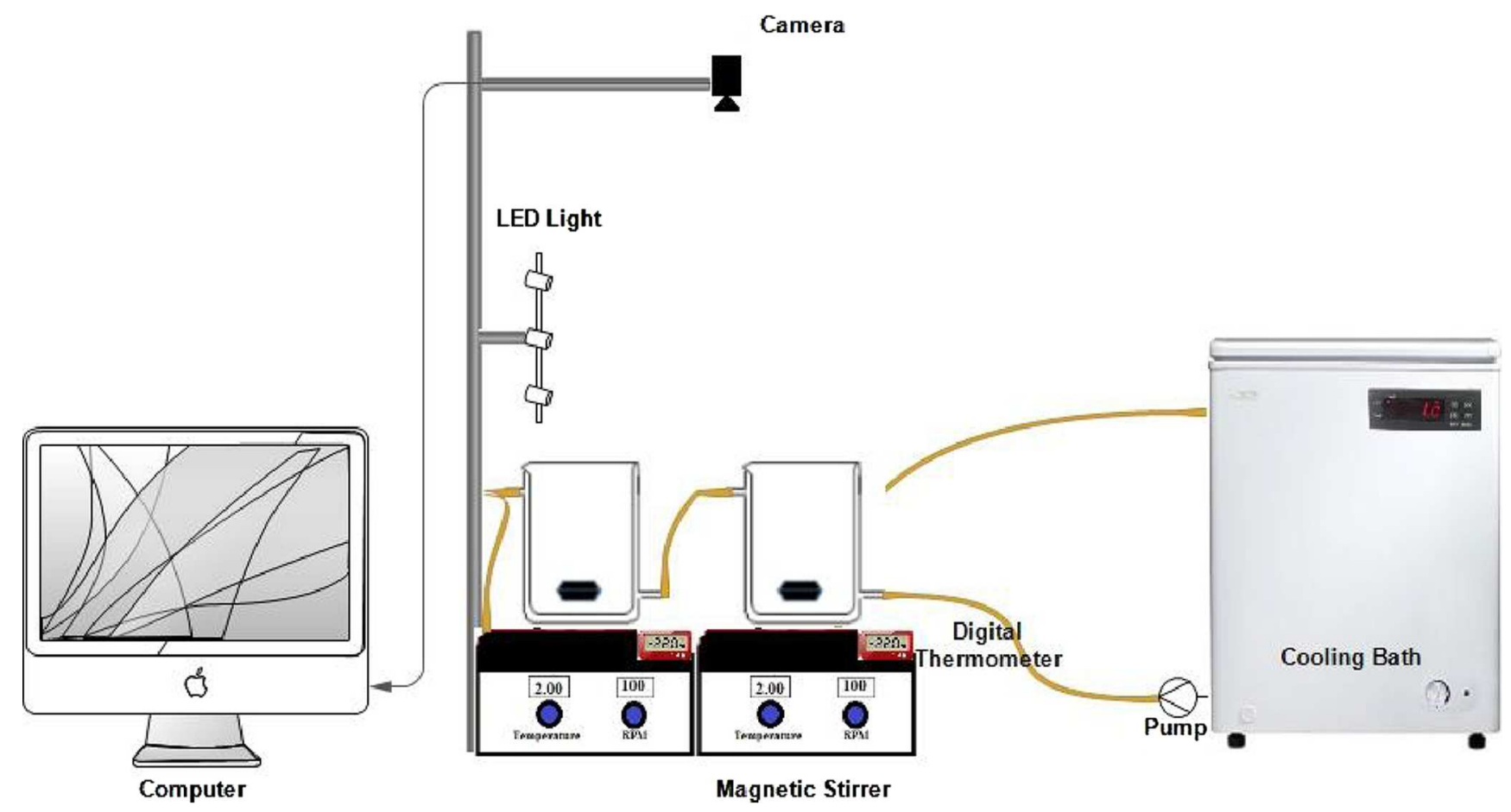

Figure 1

Experimental setup for hydrate crystal induction time measurement.

done by using a magnetic stirrer. The stirring was done at $100 \mathrm{rpm}$ to reduce the resistance in mass and heat transfer and create a homogeneous environment for hydrate crystal formation $[27,28]$. The top of the beaker was covered during the experiment with a glass plate to form a close environment and maintain the temperature homogeneity. The hydrate formation visual recording was done using a Logitech C521 webcam and to accurately measure the real time temperature of the experimental solution a digital thermometer was used. The cold bath temperature was controlled using a digital controller. The temperature of cold bath was set at $-1{ }^{\circ} \mathrm{C}$ to maintain the temperature of the experimental solution at $1{ }^{\circ} \mathrm{C}$. Two jacketed beakers are attached consecutively to the same cold bath. To minimize the temperature variation between the jacketed beakers, short insulated pipes are used and jacketed beakers are placed close to each other. The coolant flow through the jacketed beaker was started $1 / 2 \mathrm{hr}$ before the experiment, so that the temperature equilibrium can be achieved between all the jacketed beakers and after that the experimental solution was placed in the beakers. The proposed experimental setup can be modified by attaching a number of jacketed beakers for simultaneous screening of number of inhibitors. All the experiments were conducted for five times and average value of the results was considered as induction time.

\section{RESULTS AND DISCUSSION}

For the initial research and screening of hydrate inhibitors in places like academic research laboratories, a temperature augmented visual method was developed, which was more accurate and reliable in comparison to conventional visual method and other modified visual methods in determining induction time and study of hydrate inhibitors.

The hydrate inhibition efficiency of inhibitors such as Luvicap 55W (N-vinylpyrrolidone:N-vinylcaprolactam), PNIPAM, PVP and PAM were studied. The efficiency of inhibitors was determined by measuring the induction time of hydrates in the experimental solution. In all the experiments, the experimental solution used was a mixture of $25 \mathrm{ml}$ of THF and $75 \mathrm{ml}$ of distilled water/drilling mud. Formation of THF hydrates took place at readily available equilibrium temperatures of $4.4^{\circ} \mathrm{C}$ and ambient pressure [29]. THF hydrate and natural gas hydrates both forms sII hydrate structures, also, thermal \& mechanical properties of THF hydrates are similar to methane hydrates having sI structures $[6,30,31]$. Therefore, THF hydrates can be used as a replacement of methane hydrates [10, 29, 31, 32]. All the induction time measurement experiments were repeated five times and the average value of all the five runs was taken as the final induction time and shown in Table 1. 
TABLE 1

Comparison of induction time measurement obtained from convention visual method and temperature augmented visual method.

\begin{tabular}{|c|c|c|c|c|}
\hline \multirow[t]{2}{*}{ Hydrate Inhibitors } & \multirow[t]{2}{*}{$\begin{array}{l}\text { Concentration } \\
\text { (wt/vol\%) }\end{array}$} & \multicolumn{2}{|c|}{$\begin{array}{l}\text { Induction Time } \\
\quad \text { (minutes) }\end{array}$} & \multirow[t]{2}{*}{ Induction Time Difference/Error } \\
\hline & & Conventional Visual Method & Temperature Augmented Visual Method & \\
\hline \multirow{5}{*}{ Luvicap 55W } & 0.1 & 155 & 140 & 15 \\
\hline & 0.3 & 714 & 700 & 14 \\
\hline & 0.5 & $>1440$ & $>1440$ & - \\
\hline & 0.7 & $>1440$ & $>1440$ & - \\
\hline & 1.0 & $>1440$ & $>1440$ & - \\
\hline \multirow{5}{*}{ PNIPAM } & 0.1 & 107 & 95 & 12 \\
\hline & 0.3 & 476 & 460 & 16 \\
\hline & 0.5 & 1217 & 1200 & 17 \\
\hline & 0.7 & 1395 & 1380 & 15 \\
\hline & 1.0 & $>1440$ & $>1440$ & - \\
\hline \multirow{5}{*}{ PVP } & 0.1 & 92 & 80 & 12 \\
\hline & 0.3 & 215 & 200 & 15 \\
\hline & 0.5 & 1016 & 1000 & 16 \\
\hline & 0.7 & 1241 & 1230 & 11 \\
\hline & 1.0 & $>1440$ & $>1440$ & - \\
\hline \multirow{4}{*}{ PAM } & 0.1 & 08 & 10 & 02 \\
\hline & 0.3 & 08 & 10 & 02 \\
\hline & 0.5 & 11 & 12 & 01 \\
\hline & 0.7 & 09 & 14 & 05 \\
\hline
\end{tabular}

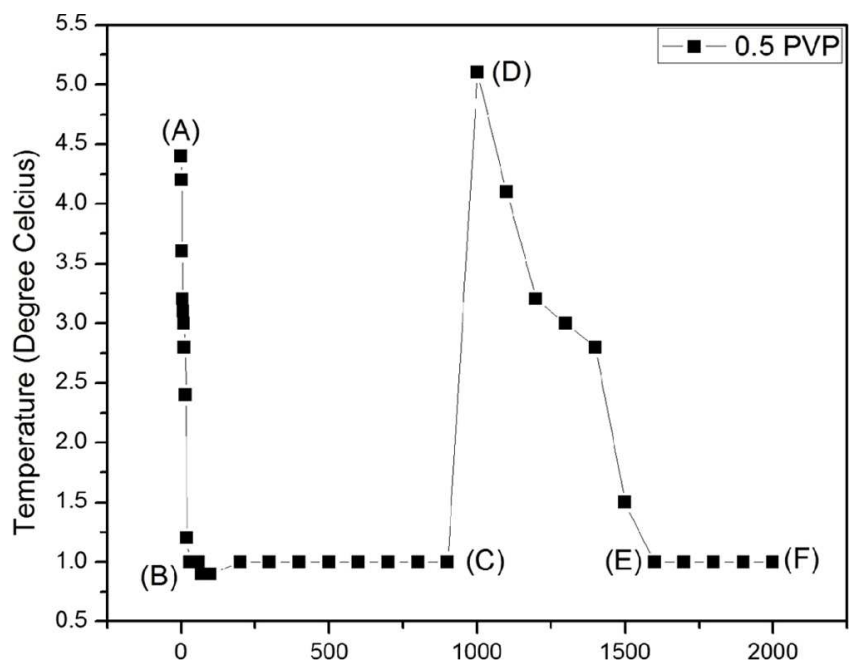

Figure 2

Determination of different stages of hydrate formation by measuring temperature variation.

\subsection{Hydrate Induction Time Studies}

THF hydrate formation can be divided into three stages: cooling stage, nucleation stage and growth stage. In the cooling stage, the temperature of the experimental solution was maintained below THF hydrate equilibrium temperature of $4.4^{\circ} \mathrm{C}$. In this research work, the temperature of the experimental solution was maintained at around $1{ }^{\circ} \mathrm{C}$. In the nucleation stage, the nucleation of hydrates took place, which is an exothermic process and increases the temperature of the experimental solution greater than or equal to the THF hydrates equilibrium temperature. The third stage, i.e. growth stage in which the completion of hydrate formation took place in the experimental solution and the temperature of the solution was varied in between the cooling temperature of $1{ }^{\circ} \mathrm{C}$ and THF hydrate equilibrium temperature. After the hydrate crystal formation in the solution, the temperature of the solution was again dropped down to the cooling temperature. These different stages of hydrate 


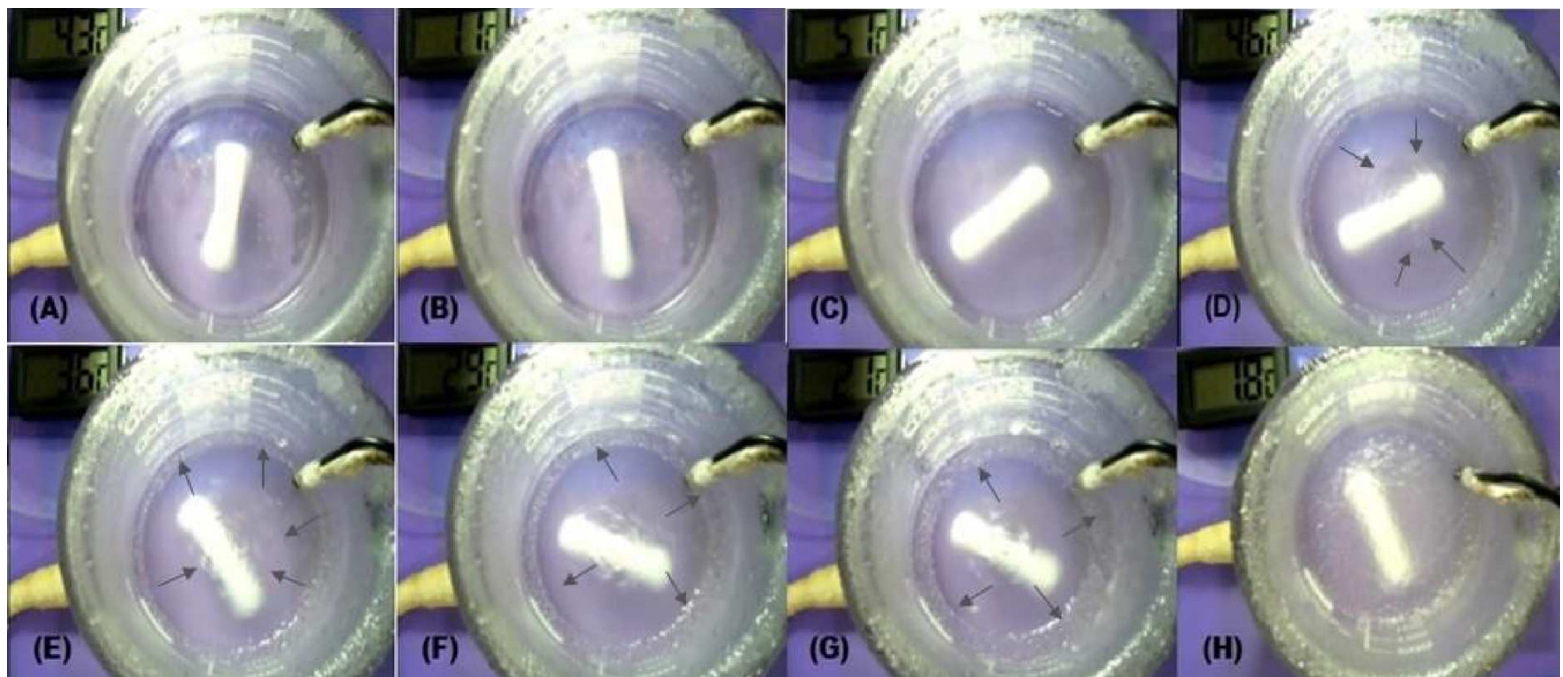

Figure 3

Pictorial view of different stages of THF hydrate formation (temperature augmented).

formation can be easily determined precisely in the visual method only if the real time temperature measurement was done consecutively. In Figure 2, stages of hydrate formation were marked according to variation in temperature of the experimental solution. The first cooling stage is from (A) to (C), second stage is the nucleation point, i.e. (D) where the first nucleation of hydrate crystal in the experimental solution took place, the third stage is the growth stage represented from (D) to (E).

In Figure 3, pictorial view of all the stages of THF hydrate was shown. The pictures (A) and (B) in Figure 3 represent the cooling stage, where no hydrate induction took place and the experimental solution remains clear. Picture (C) presents the nucleation stage of THF hydrates. At this stage, no hydrate crystals were seen in the solution with the naked eye and the detection of hydrate induction was verified only with the rise in temperature of the solution above THF equilibrium temperature. Pictures (D), (E), (F), (G) show the growth of THF hydrates in the solution with time. In the experimental solution, the hydrate crystal was visible to the naked eyes only after the picture (E) i.e. when the hydrate crystal forms cluster in the experimental solution or starts agglomerating at the walls of the beaker (represented in the picture with arrow marks). In the picture, it was seen that the agglomeration of THF hydrates took place in the form of ring structure and its size increases in each consecutive picture. Picture $3(\mathrm{H})$ represents the stage where hydrate growth was completed and the temperature of the solution was again reduced to the cooling temperature. The temperature variation in the experimental solution at each and every stage was visible in the pictures.

In the conventional visual method used for hydrate detection, the study of the temperature of the experimental solution was not performed and hence the method lags in determining the precise determination of different stages of hydrate formation in the experimental solution. Different experiments were performed using the self fabricated setup to test the hydrate inhibition efficiency of different inhibitors by determining the hydrate induction time in the experimental solution. In Table 1 the induction time determined from both the conventional visual method and temperature augmented visual method was shown. It was clearly visible that in the conventional visual method as the visual detection of hydrates in the experimental solution was difficult, leads to an error in the induction time measurement. For Luvicap $55 \mathrm{~W}$ (hydrate inhibitor) in the experimental solution the induction time determined visually was $155 \mathrm{~min}$, whereas the induction of hydrates took place in the experimental solution after $140 \mathrm{~min}$ (verified by sudden increase in temperature). Similar error in the visual determination of induction time for all the other experiments was seen. The error in the visual determination of induction time varies from approximately 11 to 17 minutes, depending upon type of hydrate inhibitors and concentration of inhibitors. When we compare the results of PAM and other inhibitors shown in Table 1, it was clear that the difference or error in induction time measurement was very small. This may be because of the fact that PAM does not have any hydrate inhibition characteristics and hence the growth of hydrate crystals in the experimental solution was very fast and clearly visible to the naked eye suddenly after induction in the solution. This also suggests that when the hydrate inhibitor efficiency was greater, then may be the error in the visual measurement of induction time was greater due to very slow growth of hydrate crystals after the induction in the experimental solution. Figure 4 shows the variation in the temperature with time of an experimental solution having different concentrations of hydrate inhibitors. With 

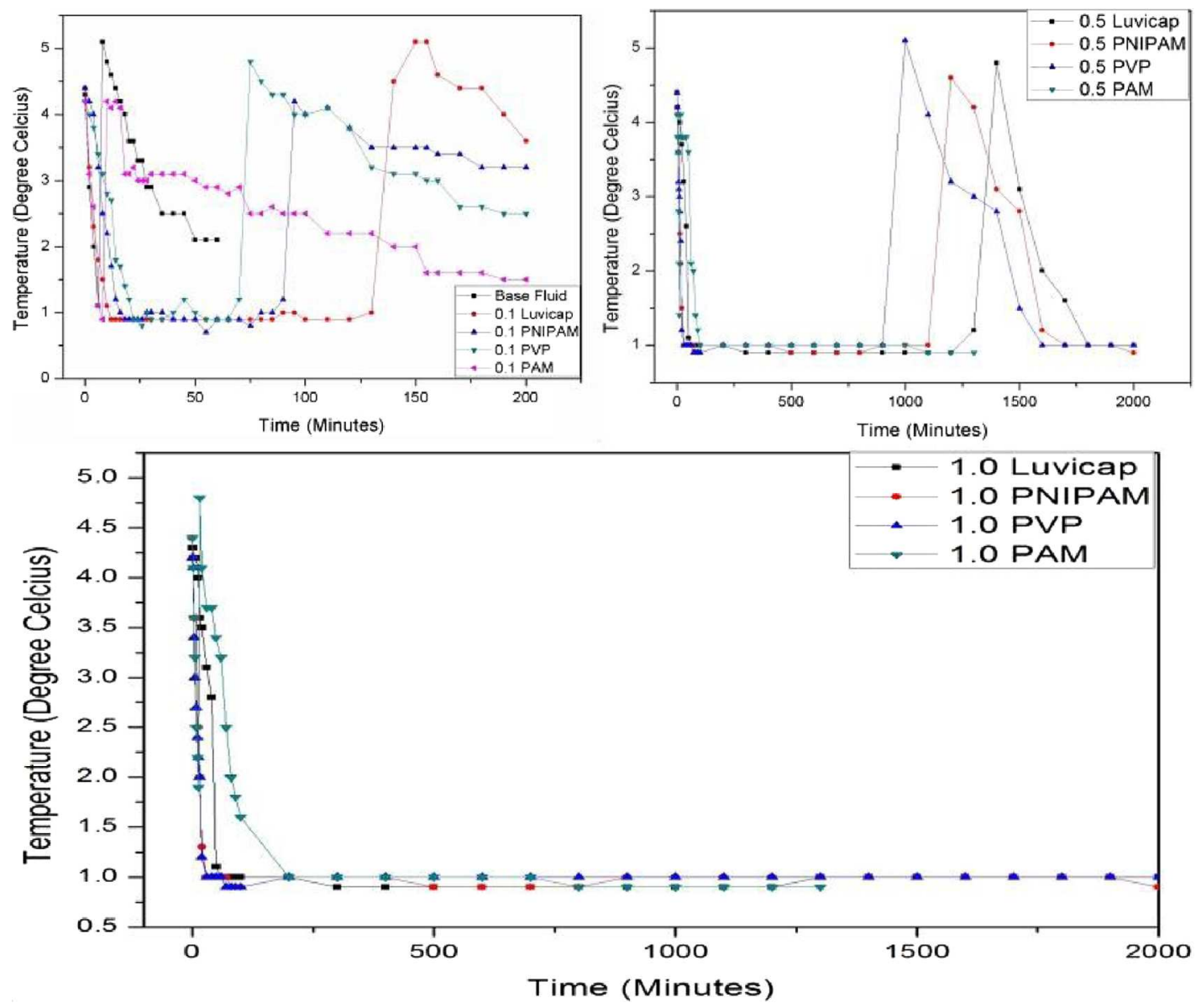

Figure 4

Temperature versus time plot of different tested hydrate inhibitors.
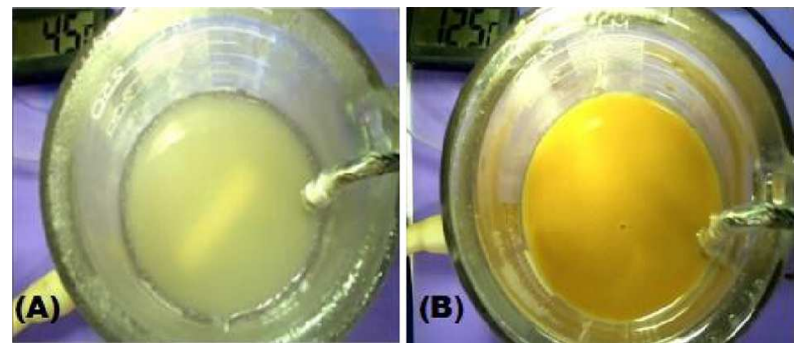

Figure 5

(A) Colored experimental solution, (B) Drilling mud.

the help of this graphical plot of temperature versus time of different inhibitors, we can easily identify different hydrate formation stages and compare different inhibitors.

Moreover, using the conventional visual method, it was very difficult to determine the induction time of hydrates in the experimental solution with additives which results in a colored solution shown in Figure 5. The same problem was faced when the additives were tested in drilling fluid solutions or drilling mud using the conventional visual method. In Figure 6, different stages of drilling fluid during the experiment was shown. It can be seen from Figure 6 that the sudden increase in temperature of experimental solution (mixture of $25 \mathrm{ml}$ THF and $75 \mathrm{ml}$ of drilling mud) was seen in picture (B), whereas hydrate crystals can only be visually identified in the picture (D). This delay results in almost $30 \mathrm{~min}$ of error in the induction time measurement, which is not acceptable. But, if we consider the temperature variation of the drilling mud solution, then we can precisely determine the induction time of hydrates. This helps in correct evaluation of different inhibitors which can be used in drilling mud as hydrate inhibitor.

\section{CONCLUSION}

The temperature augmented visual method was developed and different experiments were conducted to check its efficiency in the initial screening of hydrate inhibitors and compared with conventional visual method. Following conclusions are derived from this research work: 

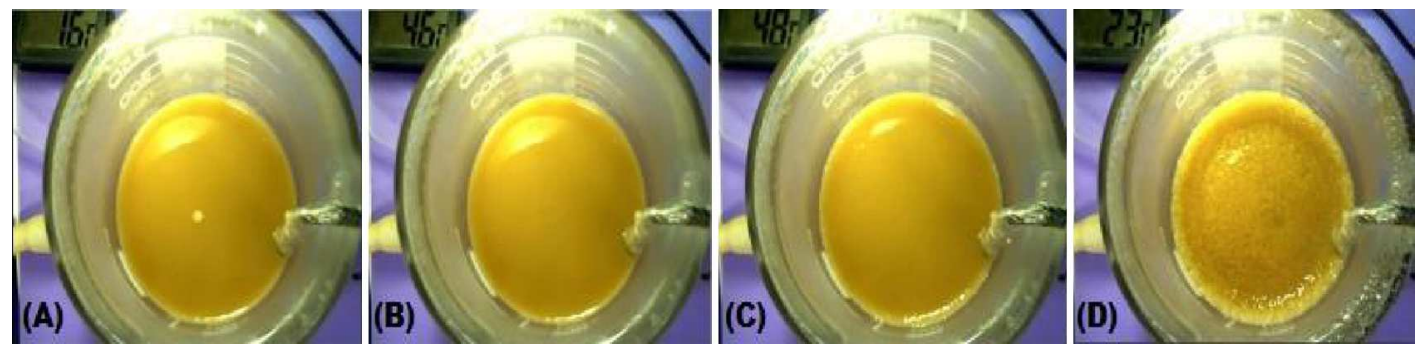

Figure 6

Different stages of hydrate formation in drilling mud (temperature augmented method).

- the temperature augmented visual method required very small sample volume, i.e. $\leq 100 \mathrm{ml}$ and can be used effectively to test costly hydrate inhibitors;

- this method accurately determines the induction time of hydrates in the experimental solution in comparison to conventional visual method;

- this method can easily and precisely determines different stages of hydrate formation in the experimental solution;

- this method can be effectively used to test the efficiency of hydrate inhibitors in the drilling mud.

The above stated conclusion shows that the temperature augmented visual method can be effectively used for initial screening of new hydrate inhibitors and precisely determine the hydrate induction time in comparison to conventional visual method.

\section{NOMENCLATURE}

$\begin{array}{ll}\text { LDHI } & \text { Low Dosage Hydrate Inhibitors } \\ \text { THF } & \text { TetraHydroFuran } \\ \text { PVP } & \text { PolyVinylPyrrolidone } \\ \text { Luvicap 55W } & \text { n-vinylpyrrolidone:n-vinylcaprolactam } \\ \text { PNIPAM } & \text { Poly(N-IsoPropylAcrylaMide) } \\ \text { PAM } & \text { PolyAcrylaMide } \\ \text { wt } \% & \text { weight percentage }\end{array}$

\section{ACKNOWLEDGMENT}

The authors would like to acknowledge the Indian Institute of Technology (Indian School of Mines), Dhanbad, India for providing financial support and necessary laboratory facilities to carry out this research work.

\section{REFERENCES}

1 Sloan E.D., Koh C.A. (2008) Clathrate Hydrates of Natural Gases, 3rd ed, CRC Press, Boca Raton.

2 Behar E., Delion A.S., Herri J.M., Sugier A., Thomas M. (1994) Plugging control of production facilities by hydrates, Ann. N. Y. Acad. Sci. 715, 94-105.
3 Ostergaard K.K., Tohidi B., Danesh A., Todd A.C. (2000) Gas Hydrates and Offshore drilling: predicting the hydrate free zone, Ann. N. Y. Acad. Sci. 912, 411-419.

4 Barker J.W., Gomez R.K. (1989) Formation of Hydrates during Deepwater Drilling Operations, J. Petrol. Technol. 41, 297-301.

5 Birchwood R.A., Noeth S., Tjengdrawira M.A., Kisra S.M., Elisabeth F.L., Sayers C.M., Singh R., Hooyman P.J., Plumb R. A., Jones E., Bloys J.B. (2007) Modeling the mechanical and phase change stability of wellbores drilled in gas hydrates, Technical Report for Joint Industry Participation Program (JIPP) Gas Hydrates Project, Phase II: Anaheim, CA, USA.

6 Kelland M.A. (2006) History of the Development of low dosage hydrate inhibitors, Energy Fuel 20, 3, 825-847.

7 Kashchiev D., Firoozabadi A. (2003) Induction time in crystallization of gas hydrates, J. Cryst. Growth 250, 499-515.

8 Koh C.A. (2002) Towards a fundamental understanding of natural gas hydrates, Chem. Soc. Rev. 31, 3, 157-167.

9 Freer E.M., Sloan E.D. (2000) An engineering approach to kinetic inhibitor design using molecular dynamics simulation, Ann. N. Y. Acad. Sci. 912, 766-776.

10 York J.D., Firoozabadi A. (2008) Comparing effectiveness of rhamnolipid biosurfactant with a quaternary ammonium salt surfactant for hydrate anti-agglomeration, J. Phys Chem. B. 112, 845-851.

11 Walker V.K., Zeng H., Ohno H., Daraboina N., Sharifi H., Bagherzadeh S.A., Alavi S., Englezos P. ( 2015) Antifreeze protein as gas hydrate inhibitors, Can. J. Chem. 93, 1-11.

12 Kelland M.A., Mady M.F. (2016) Acylamide and amine oxide derivatives of linear and hyperbranched polyethylenimines. part 1: comparison of tetrahydrofuran hydrate crystal growth inhibition performance, Energy Fuels 30, 5, 3934-3940.

13 Villano D.L., Kelland M. A. (2011) An investigation into the laboratory method for the evaluation of the performance of kinetic hydrate inhibitors using superheated gas hydrates, Chem. Eng. Sci. 66, 9, 1973-1985.

14 Duchateau C., Pou T.-E., Hidalgo M., Glenat P., Dicharry C. (2012) Interfacial measurements for laboratory evaluation of kinetic hydrate inhibitors, Chem. Eng. Sci. 71, 220-225.

15 May E.F., Wu R., Kelland M.A., Aman Z. M., Kozielski K.A., Hartley P.G., Maeda N. (2014) Quantitative kinetic inhibitor comparisons and memory effect measurements from hydrate formation probability distributions, Chem. Eng. Sci. 107, 1-12.

16 Maeda N., Fong C., Sheng Q., DaSilveria K.C., Tian W., Seeber A., Ganther W., Kelland M.A., Mady M.F., Wood C.D. (2016) High-throughput testing of kinetic hydrate inhibitors, Energy Fuels 30, 5432-5438.

17 Colombel E., Gateau P., Barré L., Gruy F., Palermo T. (2009) Discussion of agglomeration mechanisms between hydrate particles in water in oil emulsions, Oil Gas Sci. Technol. - Rev. IFP 64, 629-636. 
18 Park S.S., Kim N.J. (2013) Study on methane hydrate formation using ultrasonic waves, J. Ind. Eng. Chem. 19, 5, 1668-1672.

19 Zhou X., Fan Sh., Liang D., Wang D., Huang N. (2007) Use of electrical resistance to detect the formation and decomposition of methane hydrate, J. Nat. Gas Chem. 16, 399-403.

20 Liu Y., Song Y., Chen Y., Yao L., Li Q. (2010) The detection of tetrahydrofuran hydrate formation and saturation using magnetic resonance imaging technique, J. Nat. Gas Chem. 19, 224-228.

21 Karamoddin M., Varaminian F. (2014) Performance of hydrate inhibitors in tetrahydrofuran hydrate formation by using measurement of electrical conductivity, J. Ind. Eng. Chem. 20, 3815-3820.

22 Zeng H., Moudrakovski I.L., Ripmeester J.A. (2006) Effect of antifreeze protein on nucleation, growth and memory of gas hydrates, AIChE J. 52, 3304-3309.

23 Zeng H., Wilson L.D., Walker V.K., Ripmeester J.A. (2003) The inhibition of tetrahydrofuran clathrate-hydrate formation with antifreeze protein, Can. J. Phys. 81, 17-24.

24 Pakulski M. (1997) High efficiency non-polymeric gas hydrate inhibitors, SPE 37285. Paper presented in International Symposium on Oilfield Chemistry held in Houston.

25 Abojaladi N., Kelland M. A. (2016) Can cyclopentane hydrate formation be used to screen the performance of surfactants ad LDHI anti-agglomerants at atmospheric pressure? Chem. Eng. Sci. 152, 746-753.
26 Yang M., Song Y., Jiang L., Jing W., Liu W., Dou B. (2014) The effects of porous medium and temperature on exothermic tetrahydrofuran hydrate formation, J. Chem. Thermodyn. 78, 167-174.

27 Kashchiev D., Firoozabadi A. (2002) Nucleation of gas hydrates, J. Cryst. Growth 243, 3-4, 476-489.

28 Vysniauskas A., Bishnoi P.R. (1983) A kinetic study of methane hydrate formation, Chem. Eng. Sci. 38, 7, 1061-1072.

29 Saikia T., Mahto V. (2016) Evaluation of 1-Decyl-3Methylimidazolium Tetrafluoroborate as clathrate hydrate crystal inhibitor in drilling fluid, J. Nat. Gas. Sci. Eng. 36, 906-915.

30 Jeffrey G.A. (1984) Hydrate inclusion compounds, J. Incl. Phenom. 1, 3, 211-222.

31 Saikia T., Mahto V. (2016) Experimental investigations of clathrate hydrate inhibition in water based drilling fluid using green inhibitor, J. Pet. Sci. Eng. 147, 647-653.

32 Fereidounpour A., Vatani A. (2015) Designing a polyacrylate drilling fluid system to improve wellbore stability in hydrate bearing sediments,J. Nat. Gas. Sci. Eng. 26, 921-926.

Manuscript submitted in 1 May 2017 Manuscript accepted in 24 November 2017 Published online in January 2018 